\title{
Observational study of upper gastrointestinal tract bleeding events in patients taking duloxetine and nonsteroidal anti-inflammatory drugs: a case- control analysis
}

\author{
This article was published in the following Dove Press journal: \\ Drug, Healthcare and Patient Safety \\ 29 October 2014 \\ Number of times this article has been viewed
}

Hu Li

Yingkai Cheng

Jonna Ahl

Vladimir Skljarevski

Neurosciences, Eli Lilly and Company, Indianapolis, IN, USA
Correspondence: $\mathrm{Hu} \mathrm{Li}$

Eli Lilly and Company,

Drop Code 2638, Indianapolis,

IN 46825, USA

$\mathrm{Tel}+\mathrm{I} 317655995$ |

Fax + I 317277 I465

Email li_hu_hl@lilly.com
Purpose: To determine whether the concomitant use of duloxetine with prescription nonsteroidal anti-inflammatory drugs (NSAIDs) or aspirin was associated with an increased risk for upper gastrointestinal (UGI) bleeding compared with taking these analgesics alone.

Methods: Truven Health Analytics MarketScan Research Databases were examined for hospital admissions of adult patients indexed from January 1, 2007-December 31, 2011. Cases were patients with UGI hemorrhage or peptic ulcer disease. Controls were randomly selected from the remaining admissions to match 10:1 with cases based on age, sex, and admission date. Prescription medication exposure groups of interest were: 1) no exposure to duloxetine, NSAIDs or aspirin; 2) duloxetine only; 3) NSAIDs or aspirin only; 4) duloxetine plus NSAIDs or aspirin. Logistic regression and relative excess risk due to interaction was utilized to estimate any increased risk of UGI bleeding for patients prescribed these medications across these groups. Results: There were 33,571 cases and 335,710 controls identified. Comparing exposure group 2 and group 4, the adjusted odds ratio was 1.03 (95\% confidence interval [CI], 0.94, 1.12), and the adjusted relative excess risk due to interaction was $0.352(95 \% \mathrm{CI}:-0.18,0.72)$ for risk of UGI bleeding, neither of which support an increased risk or an interaction between duloxetine and prescription NSAID or aspirin for these events.

Conclusion: There was no evidence of an increased risk for UGI bleeding when duloxetine was taken with prescription NSAIDs or aspirin. In addition, there was no evidence of an interaction between duloxetine and prescription NSAIDs or aspirin for an increased risk of these events.

Keywords: duloxetine, upper gastrointestinal bleeding, NSAIDs, aspirin

\section{Introduction}

Selective serotonin reuptake inhibitors (SSRIs) and serotonin norepinephrine reuptake inhibitors (SNRIs) are commonly prescribed to treat depression, anxiety disorders, and premenstrual dysphoria. ${ }^{1}$ During the past decade, numerous epidemiologic reports have been published on the risk of upper gastrointestinal (UGI) bleeding as an infrequent adverse event associated with serotonin-modulating drugs. ${ }^{2-17}$ The tendency for UGI bleeding during treatment with this class of drugs is linked to impaired platelet function that is dependent on the serotonin uptake for the amplification of platelet aggregation during hemostatic thrombus formation. ${ }^{18}$

Patients with musculoskeletal pain conditions, as well as patients with depression and anxiety who experience chronic pain, may be prescribed or take over-thecounter (OTC) nonsteroidal anti-inflammatory drugs (NSAIDs), including aspirin. 
Both aspirin and NSAIDs can initiate gastroduodenal mucosal injury due to their acidic properties. ${ }^{19}$ In addition, exposure to aspirin or NSAIDs can lead to decreased mucus production, bicarbonate secretion, mucosal blood flow, epithelial proliferation, and mucosal resistance to injury. ${ }^{20,21}$ Aspirin and NSAIDs are also known to disrupt platelet function. ${ }^{18}$ Concomitant use of aspirin or NSAIDs with SSRIs or SNRIs may increase the risk for UGI bleeding. ${ }^{5}$

There is some controversy regarding the potential interaction between medications with serotonin reuptake inhibition and NSAIDs, including aspirin, which increases the risk of UGI bleeding. Some studies have suggested that there is an interaction that results in a higher risk of UGI bleeding; 3,5,6,8-10,12,14 whereas, other studies have not found an interaction. ${ }^{7,11,15-17}$ Differences in study design, data sources, study population, sample size, and study methods may account for discrepancies in the findings.

Duloxetine is an SNRI that is approved in the US and in the European Union for the treatment of major depressive disorder and generalized anxiety disorder and for the management of neuropathic pain associated with diabetic peripheral neuropathy. In the US, duloxetine is also indicated for fibromyalgia and chronic musculoskeletal pain. In a recent review of the duloxetine clinical trial safety database and the US Food and Drug Administration Adverse Event Reporting System database, Perahia et $\mathrm{al}^{17}$ found no association between the concomitant use of duloxetine with NSAIDs and increased reporting of bleeding-related adverse events when compared to NSAID use alone. Currently, there is limited real world data on the association between UGI bleeding risk and concomitant use of duloxetine with NSAIDs including aspirin. By examining a nationwide electronic health claims database, we sought to determine whether the concomitant use of duloxetine with prescription NSAIDs or aspirin was associated with an increased risk for hospitalization due to UGI bleeding events as compared with taking these analgesics.

\section{Methods}

\section{Data sources}

Truven Health Analytics MarketScan (THAM) includes the Commercial Claims and Encounters database and the Medicare Supplemental database. It captures person-specific clinical utilization, expenditures, and enrollment across inpatients, outpatients, and prescriptions from a large selection of employers, health plans, government, and public organizations in the US. Diagnoses are recorded using the
International Classification of Diseases, Ninth Revision, Clinical Modification (ICD-9-CM).

\section{Study population}

The selection of the study population is summarized in Figure 1. The study cohort included all adult patients listed in the THAM database from January 1, 2007-December 31, 2011. Encounters up to 12 months prior to each index admission were searched to identify comorbid conditions, and a 3-month window following the index date captured the inpatient length of stay and any acute postindex events. Therefore, the index of hospital admissions of the study population was between January 1, 2008-September 30, 2011. Patients were excluded if they had: esophageal varices, Mallory-Weiss syndrome, alcoholism, chronic liver disease, coagulopathies, and malignant neoplasms; were pregnant; or had a major organ transplant. Approximately 2,272 cases were estimated to provide $80 \%$ power to detect a combined additive effect of exposure to duloxetine and concomitant NSAIDs or aspirin for UGI bleeding events.

\section{Case definition and identification of controls}

Patients were included as cases if there was evidence of hospitalization for UGI hemorrhage or peptic ulcer disease, including perforation. The ICD-9-CM codes used to identify cases were: 531, gastric ulcer; 532, duodenal ulcer; 533, peptic ulcer; 534, gastrojejunal ulcer; and 578, hematemesis. Controls were randomly selected from the remaining study population base on age, sex, and the date of inpatient admission, allowing for a 30-day window to match 10:1 with cases. Patients were excluded from the control group based on the ICD-9-CM codes for blood in the stool (578.1) or hemorrhage of the gastrointestinal tract unspecified (578.9). Ten controls were selected for each case. The index date for the controls was the date of the matched inpatient admission during the intake period.

\section{Exposure variables}

The medications of interest identified from prescription claims included: duloxetine, NSAIDs (both nonselective and selective cyclooxygenase-2 inhibitors), aspirin, SSRIs, and SNRIs (other than duloxetine). Current exposure was defined as a prescription claim within 30 days before the index date. If the prescription claim occurred within 90 days prior to the index date and the days' supply associated with the claim extended into the 30-day period prior to the index date, then current exposure was assigned to that medication. 


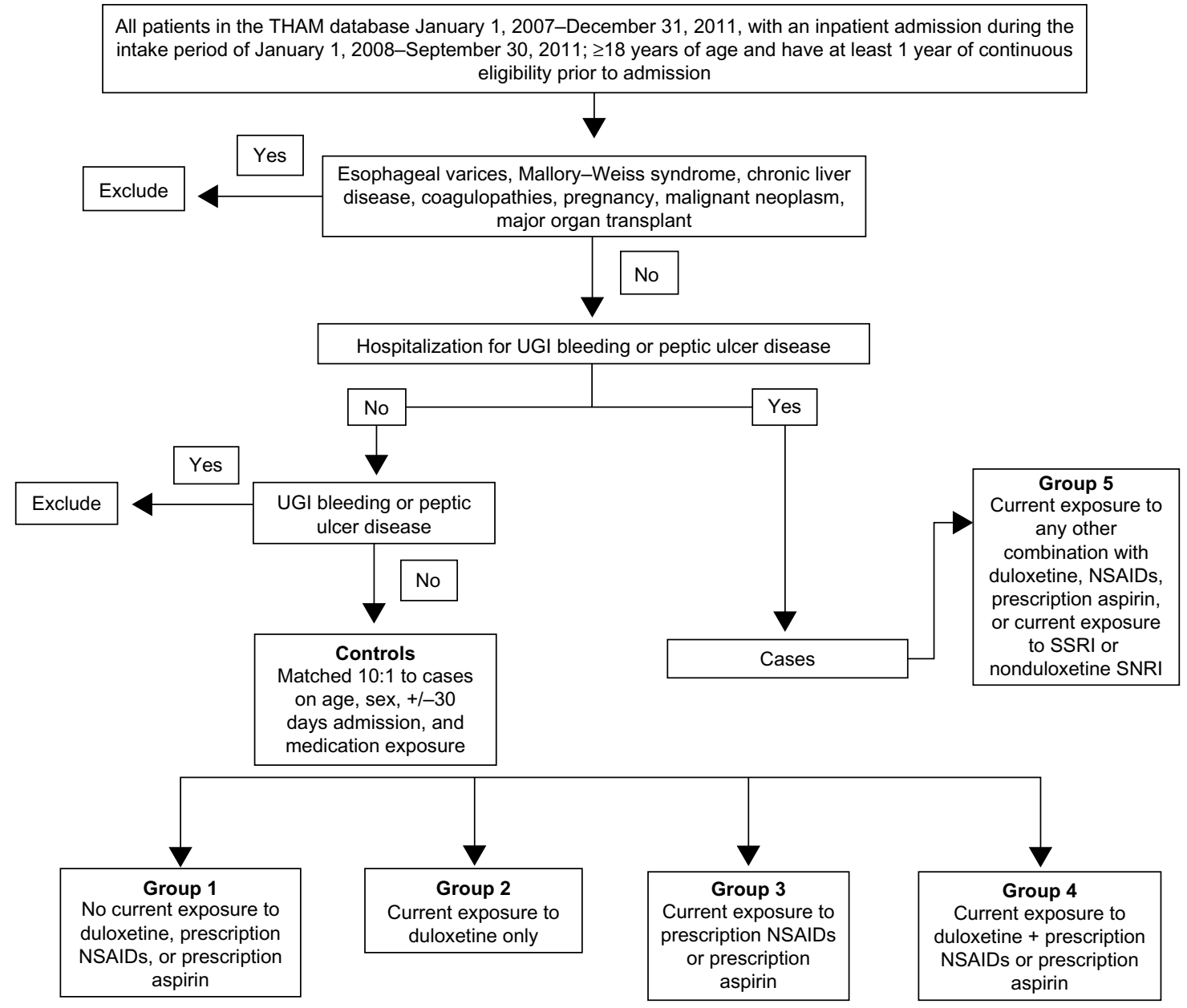

Figure I Selection of study population.

Abbreviations: NSAIDs, nonsteroidal anti-inflammatory drugs; SNRI, serotonin norepinephrine reuptake inhibitor; SSRI, selective serotonin reuptake inhibitor; THAM, Truven Health Analytics MarketScan; UGI, upper gastrointestinal.

Allowance for poor adherence to therapy was not considered when determining current exposure. Cases and controls were allocated to one of five medication exposure groups as shown in Figure 1. Group 5 patients were exposed to excluded medications or other drug combinations than those of interest, so they were not included in further analyses.

\section{Statistical analysis}

Continuous variables were summarized to report the mean and standard deviation; binary and categorical data were summarized with proportions or percentages. Relevant continuous variables were analyzed with Student's $t$-test or Wilcoxon 2-sample test with the $P$-value from the two-sided $t$ approximation. The chi-square test was used to compare binary or categorical variables.

The severity of UGI bleeding cases across all study populations were characterized through descriptive and univariate analyses. In the severity of bleed assessment, all cases were categorized according to three duloxetine dosage tiers $(<60,60$, and $>60 \mathrm{mg} /$ day $)$, and compared using a $3 \times 2$ chi-square test. The dosage tier was based on $60 \mathrm{mg} /$ day, because that is the maximum effective dose for patients with chronic musculoskeletal pain. ${ }^{22} \mathrm{~A}$ trend analysis was also conducted to assess the effects of dose across tiers. All comparisons were considered to be significant at an alpha of 0.05 .

\section{Primary analysis}

In the primary analysis, a multivariate logistic regression model was used and adjusted with the following covariates: age; sex; region; baseline comorbidity; Charlson Comorbidity Index ${ }^{23}$ current and preindex drug therapy; and health care unit utilization. Specific variables known to affect the risk of UGI bleeding were retained; whereas, model diagnostic and multicollinearity checks were applied in determining variables included in the final model. 
In a separate analysis, we calculated the relative excess risk due to interaction (RERI) ${ }^{24}$ to estimate the increased risk due to an interaction between exposure to duloxetine and exposure to NSAIDs or aspirin. The $95 \%$ confidence interval (CI) for RERI was obtained using bootstrapping. Specifically, a subset of the analytical cohort was selected, consisting of patients exposed to duloxetine only (group 2), NSAIDs or aspirin only (group 3), and duloxetine plus NSAIDs or aspirin (group 4) for bootstrapping. The covariates adjusted in these logistic regression models remained the same throughout the multivariable regression analysis. A total of 400 bootstrapping samples were used to obtain the $95 \%$ CI. Each bootstrapping sample was obtained using the following equation:

$$
\begin{aligned}
\text { RERI }= & \text { exposure }(\beta 1+\beta 2+\beta 3)-\operatorname{exposure}(\beta 1) \\
& -\operatorname{exposure}(\beta 2)+1
\end{aligned}
$$

$\beta 1, \beta 2$, and $\beta 3$ represent the coefficients from the logistic regression model for the main effect of exposure to duloxetine only (group 2), NSAIDs or aspirin only (group 3), and duloxetine plus NSAIDs or aspirin (group 4), respectively.

\section{Secondary analysis}

A secondary analysis utilized logistic regression to assess the odds ratios (OR) (95\% CIs) for UGI bleeding risk associated with exposure to the medications of interest when taken alone compared with the risk with no current exposure to those medications. Appropriate data transformation was applied on continuous covariate variables that severely deviated from a normal distribution. Due to the relatively small number of cases for UGI bleeding in some medication exposure groups and the large number of categorical predictors considered in the multivariable analysis, Firth's penalized likelihood approach was used to construct the model. ${ }^{25}$ Covariates to be adjusted in the final models were determined by the $P$-value with Wald $\chi^{2}$ tests to be $<0.05$ to remain in the models. The final models report the adjusted ORs and 95\% CIs for the groups using the no exposure group as the reference group, along with those predictors that remain in the model.

\section{Sensitivity analysis}

Prescription NSAIDs or aspirin use was anticipated to be low, because most use is OTC. Therefore, additional sensitivity analyses were conducted that simulated OTC use of these medications. Using information from the following published population surveys, point estimates for OTC NSAID/aspirin use were estimated using sex, age group, and cardiovascular disease status. The 2005 Medical Expenditure Panel Survey was used to derive estimates for OTC aspirin use. ${ }^{26}$ Data from the 2002 National Consumers League survey ${ }^{27}$ and the 2006 Slone Survey ${ }^{28}$ were used to derive estimates for OTC aspirin and NSAID use. To reduce potential bias in parameter estimates due to the randomness of assigning OTC NSAID/ aspirin use within each stratum, we replicated the process 400 times, each with a different random number generator so that, over all of the replicates, each patient would have an equal probability of being assigned as an OTC NSAID or aspirin user or nonuser, and each would have a different set of parameter estimates from the logistic regression model using the same set of predictor variables.

\section{Analysis of potential bias}

Selection bias occurs when cases and controls have different exposures to certain medication that may be due to differences in comorbidities, as well as contraindications for concomitant drug use. In particular, the use or nonuse of anticoagulants and antiplatelet agents could impact the risk of UGI bleeding. To investigate this, exposure to anticoagulants and antiplatelet agents were added (first combined and then separately) to the multivariable model.

\section{Results}

Data for 1,929,028 relevant adult patient encounters were available in the THAM database from January 1, 2007December 31, 2011. Of these patients, 33,571 cases and 335,710 controls were identified. Demographics are summarized in Table 1. The mean age for matched cases and controls was 63.1 years, and more than $50 \%$ were female. The comorbidity index was significantly higher in the case group, as was the percentage of patients with prescriptions for proton pump

Table I Baseline demographics, comorbidity index, and con-

\begin{tabular}{|c|c|c|c|}
\hline Variable & $\begin{array}{l}\text { Cases } \\
N=33,57 \text { I }\end{array}$ & $\begin{array}{l}\text { Controls } \\
N=335,7 / 0\end{array}$ & $P$-value \\
\hline Age, years, mean (SD) & $63.1(17.2)$ & $63.1(17.2)$ & 1.00 \\
\hline Female, n (\%) & $18,4 \mid 8(54.9)$ & $184,180(54.9)$ & 1.00 \\
\hline Males, n (\%) & I5, I53 (45.I) & $151,530(45.1)$ & 1.00 \\
\hline $\begin{array}{l}\text { Charlson Comorbidity } \\
\text { Index score, mean (SD) }\end{array}$ & I.8I (I.4) & $0.91(1.3)$ & $<0.0001$ \\
\hline \multicolumn{4}{|c|}{ Concomitant drug therapy, $\mathrm{n}(\%)$} \\
\hline Proton pump inhibitors & $14,228(42.4)$ & $45,388(13.5)$ & $<0.0001$ \\
\hline Glucocorticoids & $2,920(8.7)$ & $33,887(10.1)$ & $<0.0001$ \\
\hline Antiplatelet drugs & $2,558(7.6)$ & $28,612(8.5)$ & $<0.001$ \\
\hline Anticoagulants & $\mathrm{I}, 779(5.3)$ & $35,487(10.6)$ & $<0.001$ \\
\hline Estrogen/progestin & $978(2.9)$ & $12,600(3.8)$ & $<0.000$ I \\
\hline $\mathrm{H} 2$ inhibitors & $876(2.6)$ & $6,662(2.0)$ & $<0.0001$ \\
\hline
\end{tabular}
comitant drug prescriptions

Abbreviations: SD, standard deviation; $N$, total number of patients; $n$, subgroup number of patients. 
inhibitors, and H2 inhibitors. There were significantly more anticoagulants and antiplatelet agents prescribed for controls compared with cases, suggesting a potential selection bias.

The distribution of cases and controls across medication exposure study groups is summarized in Table 2. The no exposure group (group 1) was comprised of $>75 \%$ of patients identified as cases or controls. Within the duloxetine only group, most of the patients $(\sim 60 \%)$ were prescribed $60 \mathrm{mg} /$ day. There was no significant difference in prescription rates between cases and controls across the duloxetine dosage groups $(P=0.76)$ (Table 3$)$.

The frequencies of hospital procedures associated with UGI bleeding events in all cases and across doses of duloxetine in those cases exposed only to duloxetine are summarized in Table 4. Overall, the most frequent hospital procedure in the all-cases group was UGI surgery, followed by blood transfusion, and then endoscopy. Across the duloxetine dose groups, the frequencies of these procedures were lower and were not significantly different from the all-cases group. The mean length of hospital stay for cases treated with duloxetine across doses ranged from 3.3-4.4 days. In-hospital mortality for the index admission was $<1 \%$ for cases, and there were no deaths in the duloxetine dose groups. The 30-day readmission rates for UGI bleeding were higher in the duloxetine dose groups as compared with the all-cases group (49.5\% in the $60 \mathrm{mg}$ group), although totals were low and statistical significance was not observed across the dose groups. There was no evidence that the higher doses of duloxetine were associated with an increased frequency or severity of UGI bleeding events.

The results of the primary analysis are shown in Figure 2. Concomitant exposure to duloxetine plus NSAIDs or aspirin was not associated with an increased risk for UGI bleeding compared to the risk with exposure to duloxetine only (adjusted OR $=1.03$; 95\% CI: 0.94, 1.12). The adjusted RERI for UGI bleeding events with concurrent duloxetine and prescription NSAID or aspirin exposure was 0.35 (95\% CI: $-0.18,0.72)$,

Table 2 Study groups based on current exposure to prescription duloxetine, NSAIDs, or aspirin

\begin{tabular}{llll}
\hline $\begin{array}{l}\text { Study } \\
\text { group }\end{array}$ & $\begin{array}{l}\text { Medication } \\
\text { exposure }\end{array}$ & $\begin{array}{l}\text { Cases } \\
\mathbf{N = 3 3 , 5 7 I}\end{array}$ & $\begin{array}{l}\text { Controls } \\
\mathbf{N}=335,7 \text { I } 0\end{array}$ \\
& & $\mathbf{n}(\%)$ & $\mathbf{n}(\%)$ \\
\hline $\mathrm{I}$ & None & $25,688(76.5)$ & $262,627(78.2)$ \\
2 & Duloxetine only & $320(\mathrm{I} .0)$ & $3,604(\mathrm{I} . \mathrm{I})$ \\
3 & NSAIDs or aspirin only & $3,752(\mathrm{I} 3 . \mathrm{I})$ & $32,506(9.7)$ \\
4 & Duloxetine plus & $\mathrm{I} 66(0.5)$ & $\mathrm{I}, 272(0.4)$ \\
& NSAIDs or aspirin & & \\
\hline
\end{tabular}

Abbreviations: NSAIDs, nonsteroidal anti-inflammatory drugs; $\mathrm{N}$, total number of patients; $n$, subgroup number of patients.
Table 3 Doses of duloxetine prescribed across cases and controls

\begin{tabular}{lll}
\hline $\begin{array}{l}\text { Duloxetine dose } \\
\text { mg/day }\end{array}$ & $\begin{array}{l}\text { Cases } \\
\mathbf{N}=33,57 \mid\end{array}$ & $\begin{array}{l}\text { Controls } \\
\mathbf{N}=335,7 \text { I } 0\end{array}$ \\
& $\mathbf{n}(\%)$ & $\mathbf{n}(\%)$ \\
\hline$<60$ & $86(26.9)$ & $\mathrm{I}, 008(28.0)$ \\
60 & $188(58.8)$ & $2,04 \mid(56.6)$ \\
$>60$ & $46(14.4)$ & $555(15.4)$ \\
\hline
\end{tabular}

Notes: "There was no significant difference between cases and controls in prescription rates across doses. $(P=0.76)$

Abbreviations: $\mathrm{N}$, total number of patients; $\mathrm{n}$, subgroup number of patients.

which suggests that there was no interaction between these medications for an increased risk.

The adjusted ORs for UGI bleeding events for each exposure group are shown in Figure 3. The OR for an increased risk of UGI bleeding was significant only for those patients with current exposure to NSAIDs or aspirin. None of the other exposure groups were associated with an increased risk.

The sensitivity analysis with simulated OTC NSAID and aspirin exposure did not reveal any changes in UGI bleeding risk for any of the exposure groups. The NSAIDs and aspirin group remained the only group associated with an increased risk (OR: 1.14, 95\% CI: 1.12, 1.16).

\section{Discussion}

This population-based case-control study found no evidence that concomitant exposure to duloxetine and prescription NSAIDs or aspirin was associated with an increased risk of hospitalization due to UGI bleeding. In addition, RERI analyses found no evidence of an interaction between duloxetine and NSAIDs or aspirin for an increased risk for these events. These findings support other recent population-based, case-control studies, which also found no evidence of an interaction between SNRIs and NSAIDs for an increased risk of UGI bleeding..$^{711,15}$ In addition, these results lend support to a retrospective analysis of safety data that also reported no increased risk associated with concomitant duloxetine and NSAIDs or aspirin use on the incidence of UGI bleeding captured as adverse events across 55 clinical trials of duloxetine or that were reported in the US Food and Drug Administration Adverse Event System. ${ }^{17}$

The lack of an increased risk for UGI bleeding with concomitant use of duloxetine and NSAIDs or aspirin may be associated with controlling for confounding variables, such as age, sex, comorbidities associated with UGI bleeding, and the use of other medications with known UGI effects. Other studies have shown a moderate interaction when NSAIDs were taken concomitantly with SSRIs ${ }^{3,5,9,10}$ or venlafaxine, an SNRI, ${ }^{10}$ although this remains controversial 
Table 4 UGl events across all cases and each dose of duloxetine in the duloxetine-only exposure group

\begin{tabular}{|c|c|c|c|c|c|c|}
\hline UGI event & $\begin{array}{l}\text { All cases }{ }^{\#} \\
N=33,57 \text { I } \\
n(\%)\end{array}$ & $\begin{array}{l}\text { Duloxetine } \\
<60 \text { mg/day } \\
\mathrm{N}=86 \\
\mathrm{n}(\%)\end{array}$ & $\begin{array}{l}\text { Duloxetine } \\
60 \text { mg/day } \\
N=188 \\
n(\%)\end{array}$ & $\begin{array}{l}\text { Duloxetine } \\
>60 \text { mg/day } \\
\mathrm{N}=46 \\
\mathrm{n}(\%)\end{array}$ & $\begin{array}{l}P \text {-value ( } 3 \times 2 \text { chi- } \\
\text { square) }\end{array}$ & $\begin{array}{l}P \text {-value } \\
\text { trend } \\
\text { analysis }\end{array}$ \\
\hline UGI surgical procedure & $18,257(54.4)$ & $36(4 I .7)$ & 93 (49.5) & $25(54.4)$ & 0.33 & 0.14 \\
\hline Blood transfusion & $4,962(14.8)$ & $6(7.0)$ & $23(12.2)$ & $6(13.0)$ & 0.38 & 0.21 \\
\hline Endoscopy & $3,343(10.0)$ & $6(7.0)$ & $13(6.9)$ & I (2.2) & 0.46 & 0.36 \\
\hline Hospital stay in days, mean (SD) & $4.46(5.6)$ & $4.38(5.7)$ & $3.95(3.4)$ & $3.26(2.1)$ & 0.32 & 0.45 \\
\hline $\begin{array}{l}\text { Readmission for UGI bleed } \\
\text { within } 30 \text { days of discharge }\end{array}$ & $1,295(3.9)$ & $36(41.9)$ & $93(49.5)$ & $25(54.4)$ & 0.33 & 0.21 \\
\hline
\end{tabular}

Note: "There was no significant difference between cases and controls across dosage groups.

Abbreviations: UGI, upper gastrointestinal; SD, standard deviation; $\mathrm{N}$, total number of patients; $\mathrm{n}$, subgroup number of patients.

due to residual confounding. ${ }^{5,9}$ However, studies with a larger sample size and more robust methodology controlling for residual confounding variables failed to show a risk of increased UGI bleeding, ${ }^{7,13}$ or that the risk was less than previously speculated. ${ }^{15}$ The number of cases receiving venlafaxine across these studies was small, and although duloxetine was included in one study, the number of cases exposed to duloxetine was too small to provide a risk estimate. ${ }^{10}$

Neither the duloxetine exposure group nor the duloxetine plus NSAID or aspirin group was associated with a statistically significant increased risk of UGI bleeding, and there was no evidence of a duloxetine dose effect. The NSAIDs and aspirin group was the only exposure group that consistently had a significantly higher risk of UGI bleeding. Furthermore, the sensitivity analysis that used simulated OTC NSAID and aspirin exposure did not impact any of the results when included in the model.

There are limitations to this study that should be discussed. In general, observational studies based on claims databases may have missing diagnoses, prescription claims do not guarantee treatment adherence, and dosage may be missing. In addition, medical billing codes used to indicate diagnoses and procedures are subject to nonclinical influences and can result in some misclassification bias. Also, the population of patients selected for one particular treatment over another may have different characteristics. Some of these differences can be measured (such as age), but some may be unknown or not measurable.

Although selection bias was noted in our study, further data exploration found no evidence of having an impact on the primary analysis related to duloxetine and NSAID use.

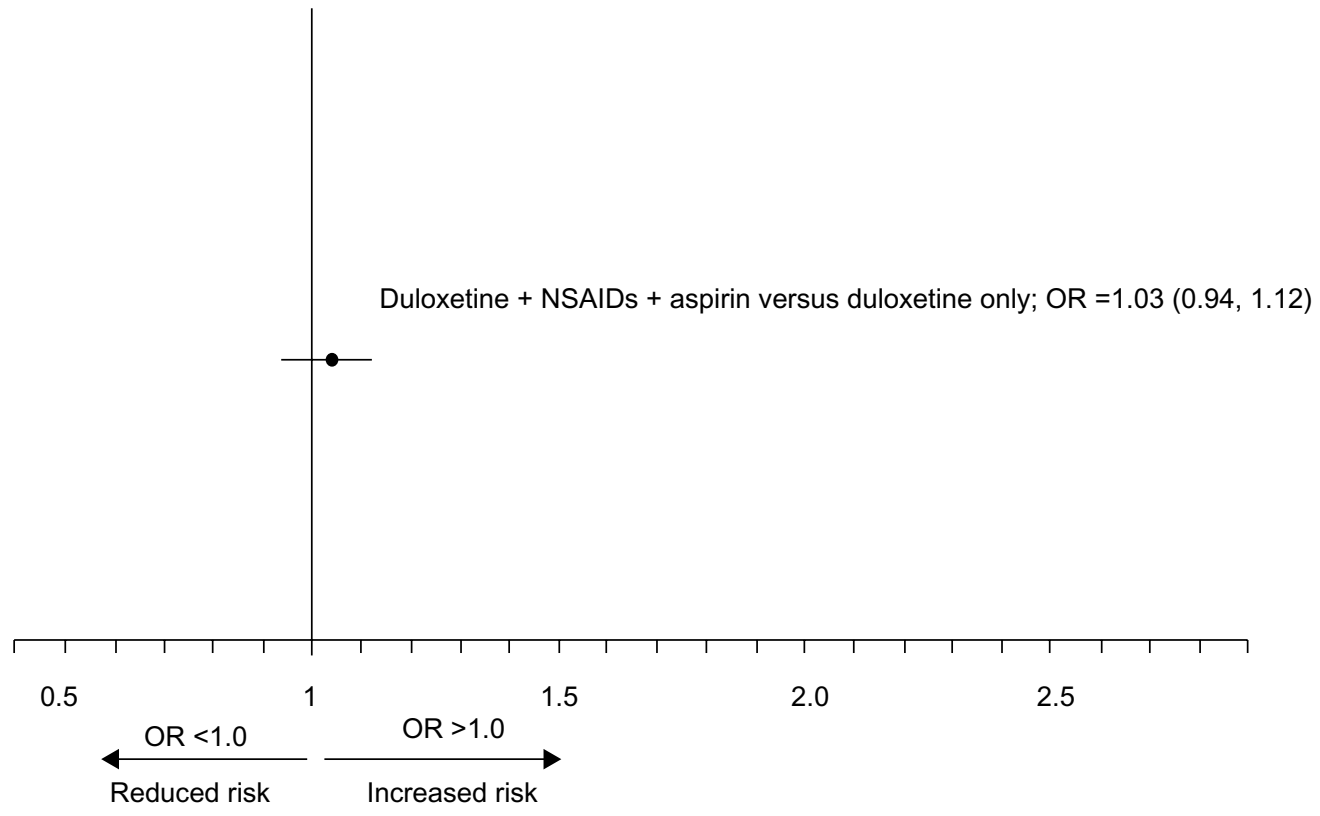

Figure 2 Adjusted OR and $95 \% \mathrm{Cl}$ for concomitant exposure to duloxetine, NSAIDs, and aspirin was not associated with an increased risk for UGI bleeding as compared with the risk from exposure to duloxetine only.

Abbreviations: OR, odds ratio; Cl, confidence interval; NSAIDs, nonsteroidal anti-inflammatory drugs; UGI, upper gastrointestinal; vs, versus. 


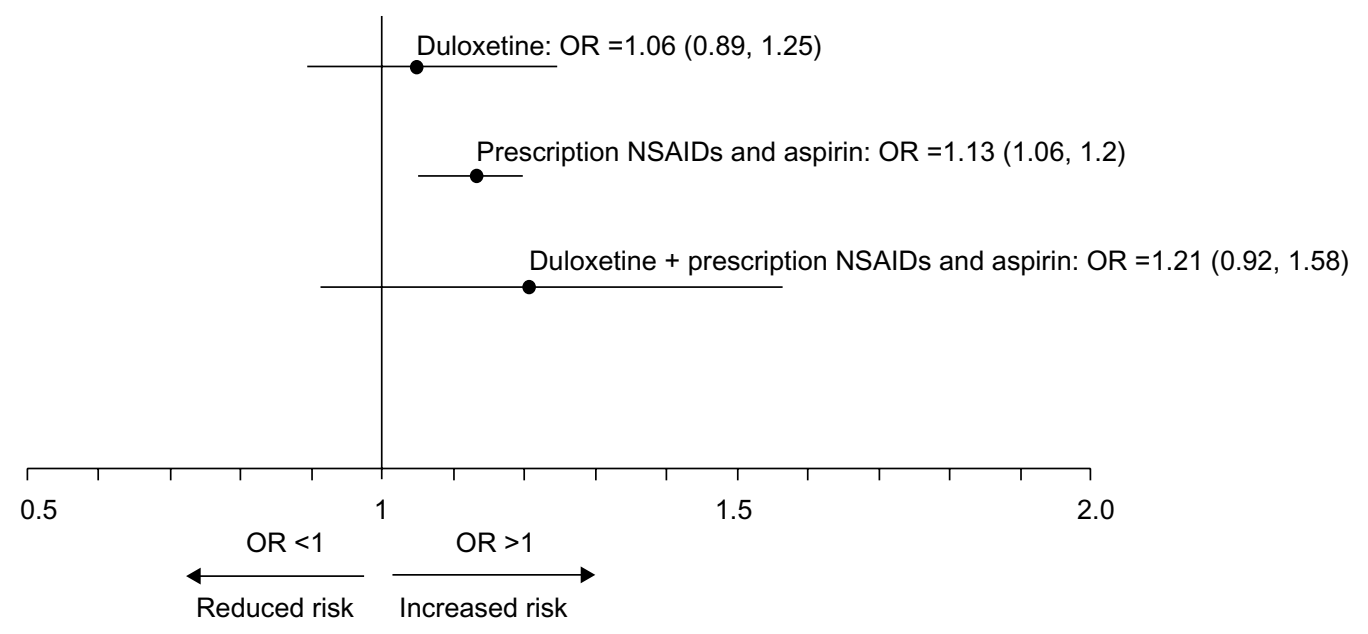

Figure 3 Adjusted OR $(95 \% \mathrm{Cl})$ for the risk of $\mathrm{UGl}$ in patients across medication exposure groups.

Note: An OR of $\mathrm{I}$ is equal to the risk of UGI bleeding in patients who had no exposure to these medications.

Abbreviations: OR, odds ratio; $\mathrm{Cl}$, confidence interval; UGI, upper gastrointestinal; NSAIDs, nonsteroidal anti-inflammatory drugs.

Lack of information on NSAID/aspirin treatment duration and dosage may have biased the outcomes, because dosage has been reported to be associated with risk of UGI bleeds. ${ }^{29}$

Also, there may be incomplete encounter histories for patients selected for the study, because some treatments may not have been captured within the data set. For example, relevant missing data include OTC medication exposure and noncovered treatment (eg, alternative medicine). However, the sensitivity analysis simulating OTC NSAID and aspirin use addressed the former with some inherent caveats. Nonetheless, research utilizing these databases provides an opportunity to expand pharmacovigilance beyond the confines of clinical trials. ${ }^{30}$

In summary, there was no evidence of an increased risk for UGI bleeds when duloxetine was taken with prescription NSAIDs or aspirin. There was also no evidence of an interaction between duloxetine and prescription NSAIDs or aspirin for an increased risk of these events. In addition, higher doses of duloxetine were not associated with increased frequency or severity of UGI bleeding.

\section{Acknowledgments}

We would like to thank Matthew F Emons, MD, and Cerner Research (Culver City, CA, USA) for constructing the analytical data file for the study population meeting study criteria. This study was funded by Eli Lilly and Company, Indianapolis, IN, USA.

\section{Disclosure}

Authors $\mathrm{Hu} \mathrm{Li}$, Vladimir Skljarevski and Jonna Ahl are employees of Eli Lilly and Company; author Yingkai Cheng is a former employee. The authors report no other conflicts of interest in this work.

\section{References}

1. Goldberg RJ. Selective serotonin reuptake inhibitors: infrequent medical adverse effects. Arch Fam Med. 1998;7(1):78-84.

2. MacDonald TM, Morant SV, Robinson GC, et al. Association of upper gastrointestinal toxicity of non-steroidal anti-inflammatory drugs with continued exposure: cohort study. BMJ. 1997;315(7119):1333-1337.

3. de Abajo FJ, Rodríguez LA, Montero D. Association between selective serotonin reuptake inhibitors and upper gastrointestinal bleeding: population based case-control study. BMJ. 1999;319(7217):1106-1109.

4. van Walraven C, Mamdani MM, Wells PS, Williams JI. Inhibition of serotonin reuptake by antidepressants and upper gastrointestinal bleeding in elderly patients: retrospective cohort study. BMJ. 2001;323(7314): 655-658.

5. Dalton SO, Johansen C, Mellemkjaer L, Nørgård B, Sørensen HT, Olsen JH. Use of selective serotonin reuptake inhibitors and risk of upper gastrointestinal tract bleeding: a population-based cohort study. Arch Intern Med. 2003;163(1):59-64.

6. de Jong JC, van den Berg PB, Tobi H, de Jong-van den Berg LT. Combined use of SSRIs and NSAIDs increases the risk of gastrointestinal adverse effects. Br J Clin Pharmacol. 2003;55(6):591-595.

7. Tata LJ, Fortun PJ, Hubbard RB, et al. Does concurrent prescription of selective serotonin reuptake inhibitors and non-steroidal antiinflammatory drugs substantially increase the risk of upper gastrointestinal bleeding? Aliment Pharmacol Ther. 2005;22(3):175-181.

8. Wessinger S, Kaplan M, Choi L, et al. Increased use of selective serotonin reuptake inhibitors in patients admitted with gastrointestinal haemorrhage: a multicentre retrospective analysis. Aliment Pharmacol Ther. 2006;23(7):937-944.

9. Helin-Salmivaara A, Huttunen T, Grönroos JM, Klaukka T, Huupponen R. Risk of serious upper gastrointestinal events with concurrent use of NSAIDs and SSRIs: a case-control study in the general population. Eur J Clin Pharmacol. 2007;63(4):403-408.

10. de Abajo FJ, García-Rodríguez LA. Risk of upper gastrointestinal tract bleeding associated with selective serotonin reuptake inhibitors and venlafaxine therapy: interaction with nonsteroidal anti-inflammatory drugs and effect of acid-suppressing agents. Arch Gen Psychiatry. 2008;65(7):795-803.

11. Lewis JD, Strom BL, Localio AR, et al. Moderate and high affinity serotonin reuptake inhibitors increase the risk of upper gastrointestinal toxicity. Pharmacoepidemiol Drug Saf. 2008;17(4):328-335.

12. Loke YK, Trivedi AN, Singh S. Meta-analysis: gastrointestinal bleeding due to interaction between selective serotonin uptake inhibitors and non-steroidal anti-inflammatory drugs. Aliment Pharmacol Ther. 2008;27(1):31-40. 
13. Vidal X, Ibáñez L, Vendrell L, Conforti A, Laporte JR; Spanish-Italian Collaborative Group for the Epidemiology of Gastrointestinal Bleeding. Risk of upper gastrointestinal bleeding and the degree of serotonin reuptake inhibition by antidepressants: a case-control study. Drug Saf. 2008;31(2):159-168.

14. Dall M, Schaffalitzky de Muckadell OB, Lassen AT, Hansen JM, Hallas J. An association between selective serotonin reuptake inhibitor use and serious upper gastrointestinal bleeding. Clin Gastroenterol Hepatol. 2009;7(12):1314-1321.

15. Targownik LE, Bolton JM, Metge CJ, Leung S, Sareen J. Selective serotonin reuptake inhibitors are associated with a modest increase in the risk of upper gastrointestinal bleeding. Am J Gastroenterol. 2009;104(6):1475-1482.

16. Maschino F, Hurault-Delarue C, Chebbane L, Fabry V, Montastrue JL, Bagheri H; French Association of Regional Pharmacovigilance Centers. Bleeding adverse drug reaction (ADRs) in patients exposed to antiplatelet plus serotonin reuptake inhibitor drugs: analysis of the French Spontaneous Reporting Database for a controversial ADR. Eur J Clin Pharmacol. 2012;68(11):1557-1560.

17. Perahia DG, Bangs ME, Zhang Q, et al. The risk of bleeding with duloxetine treatment in patients who use nonsteroidal anti-inflammatory drugs (NSAIDs): analysis of placebo-controlled trials and postmarketing adverse event reports. Drug Healthc Patient Saf. 2013;5: 211-219.

18. Scharf RE. Drugs that affect platelet function. Semin Thromb Hemost. 2012;38(8):865-883.

19. Schoen RT, Vender RJ. Mechanisms of nonsteroidal anti-inflammatory drug-induced gastric damage. Am J Med. 1989;86(4):449-458.

20. Wolfe MM, Lichtenstein DR, Singh G. Gastrointestinal toxicity of nonsteroidal antiinflammatory drugs. $N$ Engl J Med. 1999;340(24): 1888-1899.

21. Whittle BJ. Mechanisms underlying gastric mucosal damage induced by indomethacin and bile-salts, and the actions of prostaglandins. $\mathrm{Br} \mathrm{J}$ Pharmacol. 1977;60(3):455-460.
22. Pergolizzi JV Jr, Raffa RB, Taylor R Jr, Rodriguez G, Nalamanchu S, Langley P. A review of duloxetine $60 \mathrm{mg}$ once-daily dosing for the management of diabetic peripheral neuropathic pain, fibromyalgia, and chronic musculoskeletal pain due to chronic osteoarthritis pain and low back pain. Pain Pract. 2013;13(3):239-252.

23. Charlson ME, Pompei P, Ales KL, MacKenzie CR. A new method of classifying prognostic comorbidity in longitudinal studies: development and validation. J Chron Dis. 1987;40(5):373-383.

24. Richardson DB, Kaufman JS. Estimation of the relative excess risk due to interaction and associated confidence bounds. Am J Epidemiol. 2009;169(6):756-760.

25. Firth D. Bias reduction of maximum likelihood estimates. Biometrika. 1993;80(1):27-38.

26. Soni A. Aspirin Use among the Adult US Noninstitutionalized Population, with and without Indicators of Heart Disease, 2005. Rockville, MD, USA: Agency for Healthcare Research and Quality; 2007. Available from: http://meps.ahrq.gov/mepsweb/data_files/publications/st179/ stat179.pdf. Accessed June 11, 2014.

27. Wilcox CM, Cryer B, Triadafilopoulos G. Patterns of use and public perception of over-the-counter pain relievers: focus on nonsteroidal antiinflammatory drugs. J Rheumatol. 2005;32(11):2218-2224.

28. Slone Epidemiology Center, Boston University. Patterns of Medication Use in the United States, 2005. A Report from the Slone Survey. Boston, MA, USA: Slone Epidemiology Center, Boston University; 2006. Available from: http://www.bu.edu/slone/files/2012/11/ SloneSurveyReport2005.pdf. Accessed June 11, 2014.

29. Laporte JR, Ibáñez L, Vidal X, Vendrell L, Leone R. Upper gastrointestinal bleeding associated with the use of NSAIDs: newer versus older agents. Drug Saf. 2004;27(6):411-420.

30. Ryan PB, Madigan D, Stang PE, Schuemie MJ, Hripcsak G. Medicationwide association studies. CPT Pharmacometrics Syst Pharmacol. 2013;2:e76
Drug, Healthcare and Patient Safety

\section{Publish your work in this journal}

Drug, Healthcare and Patient Safety is an international, peer-reviewed open-access journal exploring patient safety issues in the healthcare continuum from diagnostic and screening interventions through to treatment, drug therapy and surgery. The journal is characterized by the rapid reporting of reviews, original research, clinical, epidemiological and

\section{Dovepress}

post-marketing surveillance studies, risk management, health literacy and educational programs across all areas of healthcare delivery. The manuscript management system is completely online and includes a very quick and fair peer-review system. Visit http://www.dovepress.com/ testimonials.php to read real quotes from published authors. 